\title{
Roadmapping as an Instrument for the Sustainable Development Planning of Amalgamated Territorial Communities
}

\author{
Volodymyr Ustymenko ${ }^{1}$, Svitlana Hrechana ${ }^{2}$, Olena Kuzmenko ${ }^{3}$, \\ Tetiana Busarieva ${ }^{4}$, Daria Zablodska ${ }^{5}$
}

\begin{abstract}
.
In the context of decentralization reform, the use of roadmapping has the particular importance for the development of amalgamated territorial communities. This visual and understandable tool for strategic planning is widely used around the world, but in Ukraine it has not become quite popular, including due to the lack of regulatory and methodological support. This article was an attempt to change this negative trend, as it proves the feasibility of roadmapping use in the planning of sustainable development of amalgamated territorial communities and offers a unified procedure for the construction of such a road map in accordance with the existing legal framework. Attention is focused on the fact that the use of any from these methods of prediction in the amalgamated territorial communities at this stage of decentralization is associated with a significant number of problems.

To improve the quality of community planning and overcome the shortage of skilled and professional staff was suggested to use the roadmapping as a process of building a kind of guide-guide or step-bystep scenario of ATC development with reflection in the graph form of strategically important events in the time sequence is proposed. It is stated that the roadmaps have significant advantages, the main of which is the visibility and clarity and are represented by a wide range of types and formats. It is proved the appropriateness of technology roadmaps usage as such, let to associate time-specific measures of development, to assess threats and opportunities, identify priorities. Proposed procedure for constructing the roadmap for the sustainable development of ATC with detailed description of each stage and a list of possible key points (nodes of the graph), which are fully correspond to the official methodological content of strategic planning of local and regional developments. Its implementation should help amalgamated communities not only to improve the quality of strategic plan and simplify its complex process, but also ensure its compliance with the current regulatory framework.
\end{abstract}

Keywords: roadmapping, sustainable development, amalgamated territorial community, decentralization, strategic planning, procedure for constructing the technology roadmap.

\section{Introduction}

Today the dominant feature of sustainable local development is the main direction of national concept of economic growth, according to which Ukraine introduced

${ }^{1}$ Corresponding Member of the National Academy of Sciences of Ukraine, Doctor of Law, Professor, Honored Lawyer of Ukraine, Director of the Institute of Economic and Legal Research of the National Academy of Sciences of Ukraine.

${ }^{2} \mathrm{PhD}$., Docent, Senior Researcher of the Department of Interregional Cooperation Problems, Institute of Economic and Legal Research, National Academy of Sciences of Ukraine.

${ }^{3} \mathrm{PhD}$., Docent, Associate professor of the Enterprise Economics Department Kyiv National Economic University named after Vadym Hetman.

${ }^{4} \mathrm{PhD}$, Docent, Associate Professor of the Department of International Economics Kyiv National Economic University named after Vadim Hetman.

${ }^{5}$ Senior Economist of the Department of Interregional Cooperation Problems, Institute of Economic and Legal Research, National Academy of Sciences of Ukraine. 
decentralization reform in 2014. Its purpose is to create capable amalgamated territorial community (ATC) on a voluntary basis, in accordance with the approved long-term plans. For its implementation, the local authorities were given the significant powers and budgets from the state bodies, including the decentralization of revenues and expenditures, the basis for the organization of effective self-management in the field. The newly created communities in the reform process not only concentrated the human, infrastructural and land resources of the merged communities, but also gained synergies by saving the financial resources from reducing the cost of management. As a result, residents of ATC were able to get better living conditions, better education and medical services, access to previously inaccessible administrative, domestic, modern transport services, and the like. The foundations for the growth of local economy and human capital have been laid. There was an increase in the participation of society in its own development, residents began to see the opportunity to change the lives of their settlements, public services approached the people, and its social standards became higher. All this has led to the increased attention of amalgamated territorial communities to the preservation of the environment and the building of resource capacity. That is, decentralization has intensified the harmonization of social, economic and environmental spheres of community life, providing the basis for sustainable development of ATC.

In such circumstances, the role of local self-government is significantly increasing, which is most close to the population both in matters of life support and control over the activities of its representatives. That is why the price of management decisions can be a prosperous future of ATC or its decline, improvement of quality of life or deterioration of living conditions, the creation of new enterprises or the collapse of existing ones. Therefore, the latest reality of amalgamated communities is created through fruitful cooperation of local governments with the public at all stages: from strategic planning to the implementation of the developed strategy and its monitoring.

Both the authorities and the public activists require clear methodological support for more effective work, since they usually do not have the appropriate professional experience in strategizing. Regulatory and methodological content (Methods for the development..., 2016; Methodological recommendations..., 2016), regulating the formation and adoption of strategies and plans for socio-economic development of amalgamated territorial communities, is fragmentary and framework - oriented advanced user who has practical experience in planning. As such, it does not provide significant assistance to ATC representatives. Therefore, they often seek advice from outside specialists and experts: the Ukrainian scientists or representatives of international programs and projects (USAID, GIZ International Services, DOBRE, DESPRO) working in Ukraine to support decentralization. For individual issues or procedures (e.g. analytical studies), it makes sense. But there are cases when the representatives of communities withdraw from the strategic planning process, which negatively affects not the quality of the formed strategy or socio-economic development plan. Given this negative experience, it would be appropriate for amalgamated communities to use a more flexible and visible strategic planning tool, roadmapping, which is often used to present an overall picture of process under study in the chain form of "expectations" - "strategy" - "development plan". 


\section{Materials and Methods}

Roadmapping is intensively used around the world from the corporate sector to the state level, but in Ukraine this method is not widely used. Although recently there has been a tendency to intensify the use of roadmaps, mainly for the presentation of government programs and the introduction of international projects (the roadmap to ensure the legislative implementation of the Association Agreement between Ukraine and the EU, the roadmap for the development of The information reintegration strategy of Donbass, the roadmap for the strategic development of trade, etc.), there is still a lack of interest in the national scientific literature on this issue. From our point of view, the lack of attention to such a powerful planning and management tool is unjustified, especially as the world experience proves its viability and effectiveness. The more urgent is study of theoretical, methodological and organizational issues of building roadmaps at the regional level in the context of decentralization.

The article investigates the method essence of roadmapping and the feasibility of its use in the field of strategic planning of sustainable development of amalgamated territorial communities in Ukraine, and offers a detailed procedure for building a roadmap of sustainable development of ATC with a description of possible nodal points.

The systematization of modern scientific research, the professional articles in periodicals and public speeches of amalgamated territorial communities representatives, allowed to characterize the main problems of strategic planning processes implementation in the ATC in the early years of decentralization reform. Their structural and logical analysis and comparison with the possibilities of existing prediction methods made it possible to propose the use of roadmapping for planning the sustainable development of amalgamated territorial communities. The further research methodology provided for the synthesis of relevant information on the nature, advantages, disadvantages and areas of application of roadmapping method in various spheres of management, for which a monographic method was used, which is usually used for a comprehensive and in-depth study of such multi-faceted objects.

The results of the preliminary stage became the basis for determining the feasibility of roadmaps usage in the field of territorial socio-economic planning and the formation for the process procedure of developing a technological roadmap for the sustainable development of amalgamated territorial communities. Further research was based on the methods of comparison and analysis (in the context of practical and theoretical experience in the development of technological roadmaps), as well as groupings and graphical method of information processing for visualization of the main stages of the procedure for building a generalized roadmap of sustainable development of ATC.

\section{Planning for sustainable development: why is the roadmapping?}

The aim of decentralization reform launched in Ukraine in 2014 is to create capable territorial communities, those " that, as a result of voluntary association, are able to independently or through the relevant local authorities to ensure an appropriate level of service provision, in particular in the field of education, culture, health, social protection, housing and communal services, taking into account human resources, financial support 
and infrastructure development of relevant administrative-territorial unit' (Methodology for the formation of capable territorial communities, 2015). One of the signs of this ability is the presence of the company's approved strategic program and target documents, namely the strategy and plan of sustainable socio-economic development.

The development strategy for the local government is the main document and despite the fact that it is a local by-law, it is necessary to strive in order to ensure that other community documents are consistent with it. Moreover, the community cannot exist separately from the region and country as a whole. Therefore, the adopted main policy document should comply with the provisions of regional development strategy and regional development Strategy of Ukraine until 2020. That is, when developing a strategy for the development of amalgamated territorial community, special attention should be paid to the internal and external interconnection of its goals and main programs.

Internal compatibility of the Strategy should be ensured by aligning its strategic and operational objectives, as well as the main local development projects, which are spelled out in the plan for the implementation of the Strategy (Strategic plan), with all the documents in force in the community that plan for sustainable development and regulate the life support of relevant territory. First of all, this applies to the territorial administration plan, the General plan for the development of territory, various sectoral programs (for example, programs that relate to the improvement of public services or public transportation, modernization of educational and health institutions).

External compatibility of company's development strategy is in accordance with the strategic and individual operational objectives of strategic documents adopted/approved at the governmental or regional level. It is not a question of subordination dependence - the power of a community does not submit to the direction in the sphere of competences to the decision of other power, except courts. However, it should take into account the decisions and plans of authorities at other levels, which may have an impact on the development of society, for example, by obtaining synergies. Ensure the coherence of community policy documents with documents of this nature, which are approved at the highest levels, makes it possible to use development programmes that operate at the central or regional level.

The desirability of compliance with the provisions of strategic documents of highest level is also that it provides access to international technical assistance programs, is the consistency of local strategy objectives with the provisions of regional or state strategy (for example, in matters of environmental protection, energy efficiency, education or social policy). This coherence is also consistent with one of the principles of the European Union's regional policy: the principle of programming. Bookmarks the European way of thinking in the process of developing a strategy for sustainable development of amalgamated territorial community, which corresponds to the implementation of the Association Agreement Ukraine - EU, will open wide opportunities for the community to participate in grant programs from international donors to Ukrainian local authorities.

Consistency of strategic and operational objectives of development strategy of amalgamated territorial community with the provisions of program documents of the regional, state and international level, will not only optimize the conditions for the implementation of strategic planning and improve its quality, but also provide the basis 
for the movement of society in the direction of its economy diversification, transformation of the community into a modern multifunctional center of comfortable life of its inhabitants, will become a stage of organic transition of ATC as a whole to a new level of sustainable development.

On the other hand, the incorporation of such high standards into the future planning process complicates the already difficult task of developing strategic policy documents in the integrated territorial communities. For a significant part of ATC, according to experts (Smentyna, 2017; Boiko, 2017), became a hindrance to the qualitative formation of strategies and plans: professional lack of training, lack of necessary knowledge and practical experience, unwillingness to learn and improve skills, lack of creative ideas for the development of development projects, imperfection and complexity of the official methodological content, incorrect organization of the strategic planning process, the use of excessive outside assistance of experts, weak public participation, and the like. Certain obstacles, especially those related to the complexity of self-development of strategic planning; necessitate the use of alternative tools to support this process, which would be obvious and understandable guide-guide within the approved procedures and in conjunction with existing programs and their own needs of society.

Such criteria are met by roadmapping, which in a general sense is a forecasting management tool. It creates a map of likely routes or paths to the desired destination (roadmap) (Kostoff \& Schaller, 2001). Unfortunately, in the scientific literature today there is no single interpretation of the essence of roadmapping method and its result of roadmap.

\subsection{Essence of roadmapping method.}

The most general interdisciplinary approach to the essence of method defines it as a business tool for strategic planning, with the help of which there is a transition from a direct understanding of any management situation and possible ways to achieve the goal to specific steps for its implementation (Garcia \& Bray, 1997). The result of this process, the developers of first roadmaps (companies and Motorola Philips) defined as 'an in-depth look into the future of singer research based on the synthesis of knowledge and imagination of key factors regarding changes in the field ... Roadmaps form a strategic vision, make it possible to attract resources at the level of companies and governments, stimulate research and monitoring processes' (Galvin, 1998). Widely views in the scientific literature view the roadmap as 'visualizing the forecast, which can be in a number of key areas, such as technology, capability, platform, system, environment, threats and business opportunities' (DeGregorio, 2000) Chi as 'predicting that it is possible or likely to happen, and plan, Express course of action' (Kappel, 2001). The essence of roadmap is seen as also 'as certain what is the evolutionary future, probably, and to refer to actions that could take these companies to compete in (or eliminate) such a future' (Gindy et al, 2006,).

Roadmapping should not be considered a tool of prediction in the literal sense. "It is rather a joint strategic planning tool that allows us to develop the strategies and take action towards the desired future, with a particular focus on forecasting changes in technology and new business opportunities" (Kamtsiuv et al, 2006).

Roadmapping is more appropriately seen as a decision-making process for planning and forecasting in social, political, international and other areas. It can be used to 
represent the development of any object: product, technology, individual company, industry, administrative-territorial unit and the like. Such a tool allows its users to quickly navigate in time and space, adhering to certain speed and timing, because the map provides all the important pointers: strategically significant events, the sequence of their occurrence, as well as the likely risks and opportunities. In general, the development of a road map is advisable if the planned strategic results of actions are not obvious. With its help, the implementation of development strategy of any object can be represented as a sequence of interrelated actions that logically follow from each other.

In the context of territorial development, namely the development of amalgamated territorial communities, under the roadmap it is proposed to determine the document, which provides a step-by-step scenario for the development of ATC, clearly presented in the graph form of management process, which reflects the strategically significant events (key points) that determine the development of society, and the sequence (timing) of their occurrence.

The process of developing such a roadmap involves the formation of a coherent vision of long-term development goals of ATC at both the general and functional level (strategic and operational). As a result, an information base for decision-making and implementation in the field of socio-economic development and a roadmap as a synthesis document in text-graphic form, containing interrelated and structured data characterizing the properties of relevant measures (programs, projects) in different periods of time.

Usually, the main purpose of roadmap is to assist in the management of forecasting and optimizing the needs and technologies needed to achieve the goals, as well as to establish a mechanism to coordinate this process. Of particular importance is the use of roadmaps in the areas of complex systems functioning. Their main advantage is the ability to present in a clear and accessible form the trajectory of mapping object development in the short and long term, as well as to show the existing alternatives. That is, it is a flexible element of decision-making that contains a shortened visual image of the entire development route with the necessary descriptions and explanations in the applications. Other key advantages and current shortcomings in the use of roadmaps are presented on Figure 1.

The defining feature that provides the benefits of roadmapping in planning the development of amalgamated territorial communities is the visibility of mapping object. The graphical and flexible nature of roadmapping reflects the clarity and consistency of specific needs at all levels, including the functional and organizational internal and external links of the community, facilitating their perception and monitoring of implementation. 


\begin{tabular}{|c|c|}
\hline Advantages & Disadvantages \\
\hline $\begin{array}{l}\text { - Roadmaps include a long-term } \\
\text { forecast of object development, broken } \\
\text { down into smaller periods, the duration of } \\
\text { which depends on the specifics of object } \\
\text { mapping; } \\
\text { - Building a roadmap to identify } \\
\text { existing capacity and gaps in development } \\
\text { planning, avoiding possible problems in the } \\
\text { future; } \\
\text { - Becomes an appropriate index- } \\
\text { reference for managers in the areas of } \\
\text { development, allowing to identify } \\
\text { intermediate the results and make } \\
\text { adjustments; } \\
\text { - With the help of roadmaps it is } \\
\text { possible to set more realistic goals and form } \\
\text { the most effective ways to achieve them; } \\
\text { - Roadmaps contain as an accurate } \\
\text { characteristic - time, which helps managers to } \\
\text { make sure that at the right time they will have } \\
\text { the resources, technologies and capacities } \\
\text { necessary for the implementation of the } \\
\text { strategy and plans; } \\
\text { - The creation of roadmaps involves } \\
\text { the exchange of information between } \\
\text { representatives of administration, business, } \\
\text { society and other parties interested in the } \\
\text { development of object, requiring the use of } \\
\text { participation method; } \\
\text { - The formation of roadmap } \\
\text { requires the development and improvement } \\
\text { of management system, which positively } \\
\text { affects the improvement of overall state of } \\
\text { the decision-making processes. }\end{array}$ & $\begin{array}{l}\text { - Complexity of construction, high } \\
\text { cost and duration of development, the need } \\
\text { to apply expertise in many areas of } \\
\text { management; } \\
\text { - The need to coordinate the work } \\
\text { of specialists from different areas and areas } \\
\text { of management; } \\
\text { - Does not answer the question: } \\
\text { who and how it will perform; } \\
\text { - The need for a significant amount } \\
\text { of analytical or statistical information, some } \\
\text { of which may not be available; } \\
\text { - Multilayer Roadmaps do not take } \\
\text { into account all aspects behind each layer or } \\
\text { level; - The existence of a significant } \\
\text { number of roadmaps forms that can be } \\
\text { modified through the needs of customers, } \\
\text { generates more questions than answers; } \\
\quad \text { - Roadmaps are normative, } \\
\text { encouraging linear thinking and using } \\
\text { established methods of development } \\
\text { planning, without encouraging developers to } \\
\text { non-standard solutions; } \\
\text { - The presence of a significant } \\
\text { number of user programs and platforms for } \\
\text { the construction of roadmaps, along with the } \\
\text { lack of a clear methodology for the } \\
\text { construction or available textbooks; } \\
\text { - Complexity of replication and } \\
\text { understanding of the result; } \\
\text { and should be constantly updated, which } \\
\text { should be done with care. }\end{array}$ \\
\hline
\end{tabular}

Figure 1. The main advantages and disadvantages of roadmaps usage

Source: Phaal et al, 2001; Wiegers, 2003; Kynkäänniemi, 2007; Lytvak, 2013; Hussaina et al, 2017

However, despite the universality of advantages and disadvantages of roadmaps, roadmapping for each specific object is a unique creative process, which is built taking into account its specificity, to ensure the success of which it is necessary to distinguish types of roadmaps.

\subsection{Types of roadmaps and their applications.}

Their classification is quite conditional because of strong relationship between the objects of mapping. In world practice, their systematization with the studied issues is widely presented, which divides the roadmaps into scientific, technological, industrial, product, scientific and industrial, product and technological, scientific and product, etc. 
(Garcia \& Bray,1997; Kappel, 2001; Albright \& Schaller, 1998). Very often, within this systematization, technological and product roadmaps are singled out in a separate group: roadmaps of environment, designed to answer questions about transformational changes in the object of mapping in the future (Schuurman, 2017; Gindy et al, 2006). There are also many classifications based on the number of measurements, context of use, purpose of forecasting, units of analysis, method and sources of data collection, form of presentation of results, etc. (Hussaina et al, 2017). Thus, in the context of this study, special attention should be paid to the typology (Phaal et al, 2009), according to which Roadmaps are divided by the method of visualization into multi-layer (for schemes and tables), singlelayer (for schemes, tables and graphs), illustrative (for flowcharts) and text.

The ukrainian researchers (Kopishynska, 2014; Tsedyk, 2015; Khaustova, 2016) focus more on the following types of roadmaps:

corporate roadmap - is aimed at planning the step-by-step development of an individual corporation, helps to unite the relevant groups of people in the company in order to develop a common vision of the future in the areas that affect their business;

industry roadmap - sets benchmarks for technological development of an industry, industry or a set of industries, identifies areas of breakthrough innovation and contains scenarios for development;

technology roadmap - plans the development of individual technologies, illustrating the programs of their long-term development; start and end points usually represent the moments in which the technology will be implemented in the final product;

product roadmap - used to identify the future needs in products and services, including latent, that is, plans to develop a product, usually a brand, corporation.

Despite the presence of significant similarities, each species has its own characteristics of construction and preferred applications. Thus, corporate roadmap will be useful for business structures created or in need of rapid development or reorganization. In contrast to the traditional business plan, such a roadmap visualizes the overall picture of business at a higher level with detailed goals and strategies to achieve them. Almost as important is the consumption of industry roadmap to strengthen competitive advantages and diversify priority sectors of economy. Product roadmap is in demand mainly by those product owners who have a desire to focus more on the final strategic goals, and not on the tactics of their achievement. Its application allows you to focus on the most valuable functions leading to the realization of the goal. And although according to statistics (Phaal et al, 2001) only 10\% of respondents developed technology roadmap, this type is the most multifaceted with respect to applications, as it supports the development and implementation of business strategies, products and technologies, providing companies with information, process and tools for their manufacture, and the like.

Thus, the English researchers Robert Phaal, Clare Farrukh and David Probert give eight most common areas of technology use, which indicates the high versatility of their application: (1)Product planning, (2) Service / capability planning, (3) Strategic planning, (4) Long-range planning, (5) Knowledge asset planning, (6) Program planning, (7) Process planning, (8) Integration planning. The most generalized type of technology roadmap is the roadmap, which refers to the implementation of production technologies, when such maps are used to communicate planned products and development technologies. The 
second direction is the map, which is similar to the first type, but becomes more useful for service enterprises, because it becomes a bridge between technology and business. The strategic planning roadmap focuses on developing a vision for the future of the business, supporting the assessment of various opportunities and threats, usually at the business level. The fourth type of map - long-term planning - broadens the planning horizon and is very often used at the national level. Planning intellectual asset is aimed at the alignment of the intellectual asset management initiatives and knowledge management with business objectives. The sixth type is program planning - focuses on the implementation of the strategy and is directly related to project planning. The following subspecies of roadmap concerns the planning of a certain component of process (for example, the development of a new product), supports the management of an intellectual asset. Integrated planning focuses on the integration and/or evolution of technology, in terms of how different technologies are combined in products and systems, or in terms of new technologies formation . (Phaal et al, 2001).

\subsection{Road mapping for sustainable territorial development.}

Having considered a detailed list of possible applications of technological roadmaps, we can conclude that this type of roadmap should be used for planning the development of amalgamated territorial communities, as they allow you to plan the development of individual technologies, illustrating their long-term development programs; start and end points. Their main advantage is that in the process of preparing the technology roadmap, there is an opportunity to assess threats and prospects, to determine priorities, and to integrate the most important factors into a coherent strategic plan.

Since technology roadmap is essentially a scenario or action plan, it provides an opportunity to link in time specific development measures in a particular area or in the appropriate direction. It is this feature that makes it possible to widely use such maps in the process of planning the development of ATG, involving the interrelated forecast and planning functions of technological roadmapping. On the one hand, with the help of technology roadmap displays the state of society development at a certain point in time, the nature, speed and direction of its forward movement. On the other hand, graphical visualization allows simplifying the choice of development vector and justifying the decision in its favor among other options.

Thus, the technological roadmap is a tool for mapping the process of long-term prediction for a significant period of time, which allows its use in strategic planning for sustainable development of amalgamated territorial communities. Its application allows to concentrate efforts of local governments on the coordinated development of society, on strengthening and realization of its potential. However, currently in Ukraine roadmapping is not enough common tools that do not have the appropriate regulatory and methodological basis, including the organization of development process. 


\section{Procedure of technological roadmap realization for the sustainable development of amalgamated territorial communities.}

Typically, a technology roadmap is built in the form of a graphical diagram or algorithm that displays the most important steps and the expected results of such steps at key points. These points are at the same time stages of development of the object, in the case of amalgamated territorial community and management decisions. The segments between them reflect the cause-and-effect relationships between objects. The main basic elements of roadmaps are: time depending on the planning horizon; nodal points and a set of layers or levels (for example, market-product-technologies-programs-resources); connections. There may also be additional information (for example, prerequisites for changes, description of the participants of the implementation phase, etc.), graphic designations (such as notes, marks, key places, gaps, opportunities, threats), and the process of moving around the map can be described.

Today there are a considerable variety of types of road maps and, consequently, software (specialized software, graphics programs, etc) to build them. At the same time, due to the peculiarities of object mapping or the individual characteristics of the responsible employees of local governments and the possibilities of information technologies used by them, new types of roadmaps may appear that have not been used before or have modified features.

On the one hand, it is good that users can choose the most convenient type of map architecture, which, in their opinion, gives a clear idea of formed vision of society development and its changes in the process of implementation. But on the other hand, this diversity creates a problem of choice. Due to the professional ignorance of many representatives of amalgamated territorial communities, who are engaged in the processes of planning the development of ATC, it is difficult to identify the most appropriate alternative. The reason is not only the lack of available educational literature or guidelines that would explain the criteria for such a choice or preference for the relevant road map, but also the lack of a more or less standard roadmapping procedure.

The world scientific literature does not give an unambiguous answer to this question, although most experts agree that the basic procedure for building a roadmap still exists. Its authors are Marie L. Garcia and Olin H. Bray, who in 1997 proposed three stages of its development: (1) Preliminary activity (satisfy essential conditions, provide leadership/sponsorship, define the scope and boundaries for the technology roadmap), (2) Development of the technology roadmap (identify the product that will be the focus of the roadmap, identify the critical system requirements and the targets, specify the major technology areas, specify the technology drivers and their targets, identify technology alternatives and their time lines, recommend the technology alternatives that should be pursued, create the technology roadmap report), (3) Follow-up activity (Garcia \& Bray ,1997).

Nathasit Gerdsri, Ronald S. Vatanan and Sasawat Dansamasatid also offer a process that involves three stages. 'Stage 1 is the initiation stage aiming to prepare an organization for the technology roadmapping process. Stage 2 is the development stage and aims to produce the roadmap by engaging the right people, gathering the necessary information, and conducting a step-by-step analysis through workshops. Stage 3 is the 
integration stage, which aims to integrate the technology roadmapping process into ongoing business planning activities so that a roadmap can be constantly reviewed and updated in a timely manner' (Gerdsri et al, 2009).

A group of British scientists (Hussaina et al, 2017) has developed a modern approach to the construction of roadmap technology, based on the synergy of scenario planning and roadmapping methods, which contains eight stages:

1. setting the scene - at this stage, the need to build a map is determined, the planning horizon is established, preparatory work with stakeholders, and, if necessary, with external specialists is conducted;

2. generate uncertainties / driving force-identification of the main driving forces in the most important categories of the environment;

3. reduce factors \& specify ranges- using the matrix of "uncertainty / impact" identifies key uncertainties for scenario development in accordance with the majority of scenarios "intuitive logic»;

4. choose themes \& develop scenarios - develop the first version of scenarios by determining the potential value of each uncertainty in each scenario;

5. check consistency of the scenarios - check the correspondence of scenarios with the help of factor analysis;

6. present scenarios - creation of narratives of the future for each scenario;

7. populate architectural framework - after getting acquainted with the uncertainties and alternatives scenarios developed move to the roadmap. Each component: external market/environment, internal business strategy, goods/services, technologies and resources is considered in several horizons;

8. identify flex points - definitions of "node points" (potential key events) in the General environment in different periods and construction of cause-and-effect relationships.

Having systematized the given research on the essence of building road maps processes, as well as based on the proposals (Kynkäänniemi, 2007; Bates et al, 2000; Gindy et al, 2006; Ansoff \& McDonnell, 1998), we propose the following vision of this procedure in the context of sustainable development of amalgamated territorial communities (Figure 2).

Thus, according to the classical approach to the roadmapping procedure, we propose to allocate three stages in it: preparation of roadmap development, development and implementation of roadmap. On the first (preparatory phase) should in the first place, to decide on the need for the roadmap in the community. The initiation of roadmapping process is associated with the identification of problems that need to be solved and the goals of roadmap development, the definition of community characteristics, the identification of stakeholders of their competencies and influence potential. It ends with the creation of a working (initiative) group and a governing body, which begin the process of forming a roadmap for the assessment of resources, funding, time required for its implementation, the collection of statistical data. This team will accompany the whole process at all stages, both in terms of the map and the planning as a whole. Also to its jurisdiction belongs to the permanent monitoring of created a roadmap with the aim of making appropriate adjustments. 
The success of organization and conduction of preparatory stage determines the effectiveness of the second stage - the development of roadmap. On the basis of the information collected by the initiative group, the main characteristics of development state of amalgamated territorial community are formulated (SWOT analysis can be used), the factors of influence and the main stakeholders, the results of public opinion (determined through a survey of the population and business) are taken into account, the prospects for development are determined. The key ones are determined by assessing the factors of uncertainty, conflict, matching benefits and costs. Then, at the same stage, the necessary architecture of the future road map is selected and the main requirements for it and the goals that it should solve are formulated. Only after that, there is a graphical representation of the results of the study - the construction of graph, links between them, as well as the preparation of the characteristics of the paths between the individual nodes of roadmap.

To simplify the work of ATC representatives and eliminate contradictions with the current regulatory and methodological content of strategic planning of local and regional development that may arise in the process of mapping, we offer a unified set of key points (nodes of the graph) for the future roadmap for the sustainable development of amalgamated territorial communities and their time parameters (Table 1).

The list of nodes is not exhaustive and permanent, it can be supplemented (for example, you can add all the meetings of the initiative group) or reduced, enlarged or, conversely, crushed. The final number of key points depends on the chosen configuration of the road map and the way it is built (expert, computer or mixed).

The implementation of roadmap - is the third stage of road mapping - begins with the presentation of the development results of roadmap for the development of society and evaluation of the presented project during public discussions in order to achieve objectivity and proper quality of the map. According to their results, the final adjustment and approval of roadmap takes place, after which the roadmap implementation plan and the monitoring system of this process are developed. It should be noted that at this stage, the degree of feedback between all roadmapping participants, the basis of which is the use of a participatory approach, plays a decisive role.

In general, the party is a kind of participation approach (the process of participation or participation of citizens) in decision-making that affect their lives in all areas. This approach is an important mechanism for the positive influence of the public on the activities of local governments, gives impetus to the search for new ideas, opportunities and resources to solve certain socially important problems, a new source of additional intellectual resource for the development of amalgamated community. That is, in terms of territorial development, the use of such an approach leads not so much to the transformation of the public space with new opportunities for communication between the population and government, as it forms an awareness of the individual responsibility of each resident for the common future of the community. 
Phase 1. Preparations for the development of roadmap

9 Determining the need for a roadmap

Initiating the process and defining the objectives of roadmap

9 Defining the characteristics of society and key needs

9 Identification of stakeholders, their competencies and potential impact

$4 \quad$ Establishment of working (initiative) group and a governing body

Assessment of resources, funding, time required for the implementation of roadmap, collection of statistical data

\section{Phase 2. The development of roadmap}

Determination of the state of society development and factors of influence of external environment

4

Determination of public opinion on the state and directions of development (questionnaire)

Identification of key issues and societal needs, capacities and barriers to development
Formation of strategic vision of development, definition of development scenarios and

4 Development of evaluation criteria or indicators to be used in the implementation of roadmap

4 Determination of resource support necessary for the implementation of events presented in a roadmap, including material, personnel, intellectual, etc

Selecting the configuration of road map and key points (nodes)

9 Graphical representation of roadmap as a graph of nodes and links between them

Preparation of the final report on the development and preparation of the characteristics of paths between the individual nodes of the map

\section{Phase 3. Implementation of roadmap} 4 Presentation of the results of roadmap development for sustainable development of the

Assessment of the draft
objectivity and quality of the card

Final adjustment and approval of roadmap
$\begin{gathered}\text { Development and realization of the roadmap implementation plan including the necessary } \\ \text { resources, deadlines, executors }\end{gathered}$
$\begin{gathered}\text { Formation of an effective system for monitoring the implementation of roadmap and } \\ \text { establishing feedback between all participants, which provide preventive adjustments }\end{gathered}$

Figure 2. Schematic representation of the procedure for building a roadmap for sustainable development of amalgamated territorial communities. Source: own elaboration 
Table 1. Key points and time parameters for building a roadmap for sustainable development of amalgamated territorial communities

\begin{tabular}{|c|c|}
\hline Key points & Period \\
\hline Formulation of vision idea for the future of society & \multirow[b]{2}{*}{ weeks $^{1-2}$} \\
\hline $\begin{array}{l}\text { The formalization of decisions on development planning. The } \\
\text { establishment of a working group }\end{array}$ & \\
\hline $\begin{array}{l}\text { The definition of sackholders, planning methodology, plan and } \\
\text { schedule }\end{array}$ & \multirow{2}{*}{ weeks $^{1-2}$} \\
\hline Organization of work and training of working group & \\
\hline Stakeholder analysis & days $^{3-5}$ \\
\hline $\begin{array}{l}\text { Development of questionnaires for the survey of residents and } \\
\text { businesses } \\
\text { Conducting a survey and processing the results }\end{array}$ & weeks $^{2-3}$ \\
\hline $\begin{array}{l}\text { Collection, systematization of data about the community. } \\
\text { SWOT-analysis }\end{array}$ & \multirow{2}{*}{ weeks $^{3-4}$} \\
\hline $\begin{array}{l}\text { Discussion of analytical results. Identification of problems and } \\
\text { needs, capacities and barriers }\end{array}$ & \\
\hline $\begin{array}{l}\text { Coordination of strategic priorities. The formation of a } \\
\text { strategic vision. }\end{array}$ & \multirow{2}{*}{ days $^{5-7}$} \\
\hline Definition of development scenarios and strategic objectives & \\
\hline Elaboration of key tasks and operational objectives. & days $^{7-10}$ \\
\hline $\begin{array}{l}\text { First edition of the draft community development Strategy and } \\
\text { its discussion }\end{array}$ & weeks $^{2-3}$ \\
\hline $\begin{array}{l}\text { Clarification of operational objectives and key projects. } \\
\text { Scheduling of strategy implementation. }\end{array}$ & days $^{5-7}$ \\
\hline Identification of funding sources and responsible persons & \multirow{3}{*}{ weeks $^{1-2}$} \\
\hline $\begin{array}{l}\text { Development of implementation, monitoring and } \\
\text { performance evaluation systems. }\end{array}$ & \\
\hline $\begin{array}{l}\text { Second edition of the draft community development Strategy. } \\
\text { Development of the plan, schedule of public consultations. }\end{array}$ & \\
\hline $\begin{array}{l}\text { Technical training and public discussions. Processing and } \\
\text { presentation of results }\end{array}$ & $\begin{array}{l}2-3 \\
\text { weeks }\end{array}$ \\
\hline $\begin{array}{l}\text { Formulation of projects for } 2 \text { years. Agreeing on the final } \\
\text { version of the Strategy }\end{array}$ & days $^{7-10}$ \\
\hline $\begin{array}{l}\text { Adoption of the Strategy by the local government. Approval } \\
\text { by the Chairman of ATC. The Publication of the Strategy }\end{array}$ & \multirow[b]{2}{*}{ weeks $^{2-3}$} \\
\hline $\begin{array}{l}\text { Start of development Plan development (strategy } \\
\text { implementation). Creation of working group. Preparation (updating) of } \\
\text { plan's analytical part }\end{array}$ & \\
\hline $\begin{array}{l}\text { Updating the mission, strategic vision, goals. Definition of } \\
\text { tasks and mechanisms for their implementation }\end{array}$ & weeks $^{2-3}$ \\
\hline $\begin{array}{l}\text { The list of current and future projects, the organization of their } \\
\text { selection. Identification of funding sources. Draft plan. }\end{array}$ & weeks $^{5-7}$ \\
\hline Technical training and public discussions. & weeks $^{2-3}$ \\
\hline
\end{tabular}


Systematization of the results of the discussions. Development of systems for the organization of execution, monitoring and evaluation of the implementation of the Plan

Implementation of tasks and development projects. Monitoring and evaluation of the implementation of the Strategy and development Plan

Source: own elaboration

Thus, the presented vision of the road mapping procedure allows to standardize the process of building a road map of sustainable development of United territorial communities. The complex procedure is presented in the form of a light-modular system, which provides for the consistent implementation of certain actions with the use of certain sets of tools, depending on the chosen architecture of roadmap and its goals. The key points (nodes of the map) are fully consistent with the current legal and regulatory field in the field of strategic planning of local and regional development, providing a link between the standardized processes of roadmapping with strategy in communities. That is, representatives of territorial communities receive an up-to-date guide-guide of their possible actions, which not only simplifies the process of sustainable development planning, but also makes it possible to make it more qualitative.

\section{Conclusions}

Summing up, it should be noted that the roadmaps are one of the modern effective tools of strategic planning in various fields, the widespread use of which has not yet occurred in Ukraine. Determined that their use allows a more systematic and reasonable to implement strategic management in helping quickly find the optimally efficient solution in terms of the limited experience of the administration, which is usually inherent in the leadership of the joint, especially the newly formed territorial communities.

Generalization of the world scientists works and practitioners studying problems of roadmapping allowed to define its essence in the context of territorial development. Under the road map to sustainable development if it is proposed to identify a document, where each step in the scenario development community is graphically represented in graph management process, which is reflected strategically important events (cue points) in determining the development of society and the sequence (timing) of their occurrence. Its graphic and flexible nature reflects the clarity and consistency of specific goals and objectives of the development of society, facilitating their perception and monitoring.

Studies of different types of roadmaps made it possible to focus on the advantages of the technological type. A detailed assessment of the areas of their possible use has shown that it is the technological road maps that are best used for planning the development of integrated territorial communities. They can be used to assess threats and prospects, identify priorities, and integrate critical factors into a coherent strategic plan. Its application allows to concentrate efforts of local governments on the coordinated development of society, on strengthening and realization of its potential.

It is determined that one of the reasons for the weak spread of road mapping in the field of sustainable development planning in Ukraine is the lack of its regulatory and methodological support, including a more or less generalized approach to the formation 
of the road map. The author's vision of such a standardized procedure, which allows you to build a roadmap of the classical form in the form of a graphical diagram showing the most important steps and the expected results of these steps in the nodal points, which are both stages of the development of ATC and management decision-making. A list of such points has also been developed, with the definition of the probable time horizon of planning. The implementation of the presented standardized procedure for building a road map for sustainable development of amalgamated territorial community will help communities not only to simplify the complex process of strategic planning, but also ensure its compliance with the current regulatory framework. The resulting road map will be a clear reflection of the whole process of strategy; will help communities that are just formed or already functioning, to avoid the negative effects of planning, which are associated with the imperfection of methodological content and lack of practical experience.

\section{References}

Albright R., Schaller R. (1998). Taxonomy of Roadmaps, Proceeding of Technology Roadmap Workshop. Office of Naval Research.Washington, DC.

Ansoff H. Ig., McDonnell J. Ed. (1998). Implanting strategic management . 2nd ed. New York : Prentice Hall, p. 520.

Bates S., Dixon W., Haley D., McCarthy J., Stone C. (2000). Voluntary Consent Order Tank and Equipment Characterization Technology Roadmap. Idaho National Engineering and Environmental Laboratory: Working Paper, INEEL/EXT-2000-01218.

Boiko Al. Planning of the regional development in Ukraine (2017). Herald of Kyiv National University of Trade and Economics. Vol. 1. pp. 19-35. [in Ukrainian].

Cabinet of Ministers of Ukraine (2015). On the Voluntary Association of Territorial Communities. Resolution 214 from April 8,2015. Retrieved from https://zakon.rada.gov.ua/laws/show/214-2015-0D0\%BF

DeGregorio G. (2000). Technology Management via a Set of Dynamically Linked Roadmaps. Proceedings of the 2000 IEEE Conference, Albuquerque: New Mexico. pp. 184-190. doi: 10.1109/EMS.2000.872498

Hussaina M., Tapinosb E., Knighta L. (2017). Scenario-driven roadmapping for technology foresight. Technological Forecasting \& Social Change. Vol. 124. pp. 160-177. https://doi.org/10.1016/j.techfore.2017.05.005

Galvin R. (1998). Science Roadmaps. Science. Vol. 280, Issue 5365, p. 803. doi: 10.1080/09537325.2013.832744

Gerdsri, N., Vatananan, R.S., Dansamasatid, S. 2009. Dealing with the dynamics of technology roadmapping implementation: a case study. Technol. Forecast. Soc. Chang. 76, 50-60.

Gindy N. Z. N. \& Cerit B.\& Hodgson A. (2006). Technology roadmapping for the next generation manufacturing enterprise. Journal of Manufacturing Technology Management. Vol. 17(4). pp. 404-416. doi: https://doi.org/10.1108/17410380610662843

Ministry of Regional Development, Construction and Housing and Communal Services of Ukraine (2016). On approval of the Methods for the development, monitoring and evaluation of the implementation effectiveness on regional development strategies and action plans for their implementation. Order 79 from March 30, 2016. Retrieved from https://zakon.rada.gov.ua/rada/show/v0075858-16

Ministry of Regional Development, Construction and Housing and Communal Services of Ukraine (2016). On approval the Methodic recommendations on the formation and implementation of the forecast and program documents of the socio-economic development of the amalgamated territorial community. Order 75 from March 30, 2016. Retrieved from https://zakon.rada.gov.ua/laws/show/z0632-16.

Kamtsiou V. \& Naeve A. \& Stergioulas L. \& Koskinen T. (2006). Roadmapping as a knowledge creation process: The PROLEARN roadmap. Journal of Universal Knowledge Management. Vol. 1. No. 3. pp. 163-173.

Kappel T.A. (2001). Perspectives on roadmaps: How organizations talk about the future. Journal of Product Innovation Management. Vol. 1 (18). p. 39-50. doi: 10.1111/1540-5885.1810039. 
Khaustova V.Ye. (2016). Theoretical and methodological foundations of roadmaps as a modern tool for strategic planning of socio-economic processes. Business Inform. Vol. 8. pp. 140-153. [in Ukrainian].

Kopishynska K.O. (2014). Roadmap as a tool for determining the strategy of innovative development of engineering enterprises. Business Inform. Vol. 11. pp. 88-94. [in Ukrainian].

Kostoff R. N. \& Schaller R. R. (2001). Science and Technology Roadmaps. IEEE Transactions on Engineering Management. Vol. 48, No. 2, pp. 132-143. doi: $10.1109 / 17.922473$

Kynkäänniemi T. (2007). Product Roadmapping in Collaboration. VTT Publications. p. 625.

Lytvak B.H. (2013). Strategic management: a textbook for bachelors. Moscow.Yurait. p. 507. [In Russian]

Marie L. Garcia and Olin H. Bray. (1997). Fundamentals of technology roadmapping. Albuquerque, NM: Sandia National Laboratories.

Phaal R. and Farrukh CJP and Probert DR (2001). Characterisation of technology roadmaps: purpose and format. Technology Management in the Knowledge Era. Institute of Electrical and Electronics Engineers \& Portland International Centre for Management of Engineering and Technology, pp. 367-374. doi: $10.1109 /$ PICMET.2001.952036

Phaal R., Farrukh C. and Probert D. (2001). Technology Roadmapping: linking technology resources to business objectives. Center for Technology Management, University of Cambridge.

Phaal R., Farrukh C.J., Probert D.R. (2009). Visualising strategy: a classification of graphical roadmap forms. Int. J. Technol. Manag. Vol. 47. pp. 286-305. https://doi.org/10.1504/IJTM.2009.024431

Schuurman R. Tips for Agile product roadmaps \& product roadmap examples. Retrieved from https://www.scrum.org/resources/blog/tips-agile-product-roadmaps-product-roadmap-examples

Smentyna N.V. (2017) Strategic planning at the level of amalgamated territorial communities. Ekonomichni innovatsii: zbirnyk naukorykh prats. Vol. 64. pp. 287-292. [in Ukrainian].

Tsedyk M. (2015). Selection of methods for regional foresight. Actual problems of public administration. Vol. 4(64). pp. 37-42. [in Ukrainian].

Wiegers K.E. (2003). Software Requirements. Practical Techniques for Gathering and Managing Requirements throughout the Product Development Cycle. 2nd ed. Redmond. Washington: Microsoft Press. 